Vol. 7 No. 1, April 2021 (48-54)

JURNAL KEOLAHRAGAAN

https://jurnal.unigal.ac.id/index.php/JKP

\title{
Pengaruh Efektivitas Penilaian Sistem Digital Pertandingan Pencak Silat Berbasis Komputer Dengan Sistem Penilaian Manual
}

\author{
Muhammad Nurzaman dan Isna Daniyati Nursasih \\ Program Studi Pendidikan Jasmani, Universitas Galuh, Ciamis, Indonesia \\ Email: mnurzaman3@gmail.com
}

\begin{abstract}
The purpose of this study was to determine the effectiveness of the influence of computer-based digital assessment systems which are now often used in pencak silat competitions compared to manual system assessments. The research method used in this research was descriptived method with the research sample, namely the referees of the jury who were carrying out a pencak silat competition at PPLM Unpad with a questionnaire research design. The instrument used in this studied was a closed questionnaire in the form of a choice of five answer options that were already available in the questionnaire and this questionnaire used a rating-scale measurement that can show a comparison of the quality of the tool. From the research results, it was known that the effectiveness of the assessment of the computer-based digital system has a value of 852 , while the effectiveness of the manual system assessment is around 773 and the average quality value of the computer-based digital system assessment is around 4.9 and the manual system assessment is 4.6 we could compared -The rate of assessment for computer-based digital systems was higher than that of manual systems. This shows that the computer-based digital assessment system was better for used in pencak silat matches.
\end{abstract}

Keywords: Computer based pencak silat, Evaluation effectiveness

\begin{abstract}
ABSTRAK
Tujuan penelitian ini adalah untuk mengetahui keefektivan pengaruh penilaian sistem digital berbasis komputer yang sekarang sering digunakan dalam pertandingan pencak silat dibandingkan dengan penilaian sistem manual. Metode penelitian yang digunakan dalam penelitian ini adalah metode deskriftif dengan sampel penelitiannya yaitu para wasit juri yang sedang melaksanakan pertandingan pencak silat di PPLM Unpad dengan desain penelitian angket. Instrumen yang digunakan dalam penelitian ini adalah angket tertutup berupa pilihan lima option jawaban yang sudah tersedia di dalam angket dan angket ini menggunakan pengukuran rating-scale yang dapat memperlihatkan perbandingan kualitas alat. Dari hasil penelitian diketahui bahwa efektivitas penilaian sistem digital berbasis komputer terdapat nilai dengan 852 sedangkan efektivitas penilaian sistem manual berkisar 773 dan rata-rata kualitas nilai penilaian sistem digital berbasis komputer berkisar 4,9 dan penilaian sistem manual adalah 4,6 bisa kita bandingkan bahwa rata-rata penilaian sistem digital berbasis komputer lebih tinggi di bandingkan dengan sistem manual. Hal ini menunjukan bahwa penilaian sistem digital berbasis komputer lebih bagus untuk digunakan pada pertandingan pencak silat.
\end{abstract}

Kata Kunci: Efektivitas Penilaian, Pencak Silat, Berbasis Komputer.

Cara sitasi:

Nurzaman. M. Nursasih. I. D. (2021) Pengaruh Efektivitas Penilaian Sistem Digital Pertandingan Pencak Silat Berbasis Komputer Dengan Sistem Penilaian Manual. Jurnal Keolahragaan Pendidikan Jasmani. Unigal, 7(1), 48-54. 


\section{PENDAHULUAN}

Pencak silat adalah salah satu cabang olah raga bela diri yang asli dilahirkan di rumpun melayu, khususnya Indonesia. Pada dasarnya pencak silat hanya digunakan untuk melindungi dari segala ancaman, dan untuk berperang melawan penjajah. Maka bela diri pencak silat haruslah kita budi dayakan keaslianya oleh kita agar, tidak punah di makan oleh zaman yang berkembang sekarang ini. Pencak silat adalah salah satu bela diri untuk memepertahankan kehidupan salah satu kelompoknya dari tantangan alam, gangguan binatang dan manusia sekitarnya. Pendapat yang sama menurut Mr. Wongsonegoro ketua IPSI yang pertama dalam Sucipto, (2001:26-28) mengatakan bahwa : "Pencak adalah gerakan serang bela, berupa lari dan berirama dengan peraturan adat kesopanan tertentu, yang biasa dipertunjukan di depan umum. Silat adalah inti sari dari pencak, yakni kemahiran untuk perkelahian atau membela diri mati-matian yang tidak dapat dipertunjukan di depan umum". Caranya pembelaan diri itu selalu digunakanya. Semua itu hanya untuk mempertahankan hidupnya di dunia ini seperti yang kita tahu, di dunia penuh dengan bahaya - bahaya yang tak terduga dan mengancam kelangsungan hidup kita.

Mengapa harus digunakan? Karena sebagai salah satu mahluk hidup harus mempertahankan kelangsungan hidupnya, Harus bisa lolos dari berbagai ancaman kematian yang siap untuk merenggut kehidupan kita di dunia ini, ancaman kepunahan dalam kehidupan yang terus membayangi kita di dunia ini. Notosoejitno (1997: 34) mengatakan, Pencak Silat : "Untuk menggambarkan ribuan pribumi melawan gaya yang ada di seluruh Malay Archipelago, yang meliputi Indonesia, Malaysia, Singapura, Brunei Darussalam, Thailand Selatan dan Filipina Selatan". Oleh karena, itu setiap manusia harus mempunyai salah satu keahlian bela diri untuk tetap bisa bertahan hidup dari gangguangangguan yang tidak terduga atau pencak silat yang harus tetap kita jaga kelestarianya. Di dalam pencak silat ada kebudayaan seni bela dirinya untuk tetap dikembangkan di dunia pencak silat. Dijelaskan bahwa pencak silat mempunyai ciri khusus, yaitu :

1. Mempergunakan kelentukan, kelicahan, kecepatan, saat/timing dan sasaran yang tepat dengan gerakan yang cepat untuk menguasai lawan, bukan mutlak dengan kekuatan besar.

2. Mempergunakan prinsip timbang badan, permainan posisi, dengan memindahkan titik berat badan.

3. Memanfaatkan siap serangan lawan dan tenaga lawan.

4. Mengeluarkan tenaga sendiri sedikit mungkin, hemat, simpan tenaga.

Perkembangan yang pesat, adat istiadat, dan perbedaan kondisi lingkungan melahirkan aliran-aliran dalam pencak silat. Beralih kejaman kerajaan di Indonesia, Pencak silat dilatih kepada para prajurit untuk mempertahankan intergritas kerajaan dan perluasan daerah kekuasaan, dengan didukung perlengkapan persenjataan maka akan kokoh kerajaan tersebut. PB IPSI beserta BAKIN pada tahun 1975 dalam Sucipto, (2001:26-28) mendefinisikannya sebagai berikut : "Pencak silat adalah hasil budaya manusia Indonesia untuk membela, mempertahankan eksistensi (kemandiriannya) dan integritasnya (manunggal) terhadap lingkungan hidup/alam sekitarnya untuk mencapai keselarasan hidup guna peningkatan iman dan taqwa kepada Tuhan Yang Maha Esa”. Pada zaman penjajahan digunakan untuk melawan penjajah yang untuk menguasai daerah yang kita tempati makanya waktu itu penjajah tidak menghendaki perguruan-perguruan pencak silat untuk berdiri karena dianggap membahayakan bagi para penjajah untuk menguasai daerah kita, akhirnya pesantren dan surau sebagai wadah untuk berkumpulnya para pejuang.

Semakin berjalanya waktu maka perkembangan IT (Ilmu Tehnologi) semakin berkembang. Begitupun di pencak silat maka banyak perubahan-perubahan yang signifikan dalam cara penilaian bagi para juri dalam suatu pertandingan di gelanggang 
arena pencak silat. Williams dan Sawyer (2003) "TI adalah teknologi yang menggabungkan Komputer dengan jalur komunikasi yang berkecepatan tinggi yang dapat membawa data, suara dan video". Maka penelitian ini agar, dapat mempermudah juri pencak silat menilai atlet yang sedang bertanding dengan hanya menekan tombol angka yang sudah dimodifikasi kedalam penilaian pencak silat dan langsung tertera penilaiannya di layar proyektor dibandingkan dengan cara penilaian yang biasa saja seperti halnya pemakaian yang manual para juri harus menilai dengan pulpen dan kertas dan harus menjumlahkan penilaian akhir dengan sendirinya.

Selain dari pada itu sistem digital berbasis komputer ini memberikan penilaian secara transparan di semua pihak maka penelitian ini sangat bagus untuk kedepanya bagi dunia pencak silat untuk bisa bertahan di dunia yang semakin terus maju dalam Ilmu Tehnologi. Para juri yang memberikan penilaian yang akan berbuat penyimpanganpenyimpangan terhadap atlet yang sedang bertanding, oleh dewan juri akan dipanggil untuk di berikan teguran kepada juri yang menilai agar, memberikan nilai secara objektif sedangkan penilaian secara manual masih saja ada kekurangan-kekurangan yang signifikan yang dapat membuat para juri pencak silat harus objektif untuk memberikan penilaian yang akan menimbulkan ke tidakpuasan dalam penilaian di berbagai pihak. Langkahlangkah ini sangat bagus ke depanya untuk memberikan kontribusi dan kemajuan IPTEK kepada perkembangan cabang olah raga pencak silat.

Oleh karena itu, perlu pengembangan yang signifikan melalui dukungan yang terintregrasi dari berbagai semua pihak yang mengaplikasikan ilmu tehknologi untuk tujuan memperkenalkan sistem digital berbasis computer ini di dunia pencak silat dan sistem digital berbasis computer ini sudah di sahkan pada RAKERNAS Bulan Mei 2010 Di Surabaya. Semoga kedepan perkembangan pencak silat di internasional pencak silat dapat diakui dan lebih mengeksitensinya dalam mempromosikan bela diri pencak silat. Semua itu bekerja keras dengan bidang ilmu tehnologi untuk menerapkan upayanya sport sciences dengan menerapkan tehnologi sistem computer penilaian pertandingan sehingga mempermudah proses jalanya pertandingan.

Penelitian sistem digital pertandingan pencak silat berbasis computer ini ada juga keuntunganya. Jika dilihat secara pengenalan kepada dunia pencak silat khususnya, sistem digital pertandingan silat berbasis computer dapat digunakan untuk mempromosikan iklan, untuk menambah sponsor-sponsor dipertandingan pencak silat tersebut. Sistem digital berbasis computer dapat dilihat oleh semua penonton pertandingan pencak silat saat itu. Penelitian ini dapat berdampak positif dalam kejuaraan pencak silat yang akan membuat pertandingan pencak silat lebih menarik untuk ditonton oleh semua orang. Para sponsorsponsor yang ingin memasang iklannya di kejuaraan pertandingan pencak silat secara otomatis dapat memperkenalkan produknya kepada masyarakat, sehingga saling menguntungkan antara pihak sponsor dan panitia kejuaraan pencak silat. Dengan demikian sponsor-sponsor terus memberikan dukungan kepada pencak silat untuk terus berkembang dengan didanai oleh sponsor-sponsor yang besar. Semakin banyak sponsor-sponsor atau perusahaan berdatangan yang ingin melakukan kerja sama dengan pencak silat, maka akan semakin ramai dalam pertandingan pencak silat.

\section{METODE PENELITIAN}

Metode penelitian yang digunakan pada penelitian ini adalah metode deskriftif dan desain yang digunakan pada penelitian ini adalah desain kuantitatif dengan menggunakan angket/kuesioner dengan cara jawaban tertutup. Populasi yang akan diambil pada saat Kejuaraan pencak silat PPLM di UNPAD Bandung Se-Nasional pada Tahun 2010 sedangkan sampel yang digunakan oleh peneliti secara purposive sampling dikarenakan peneliti beranggapan bahwa pengujian harus valid dimana yang diambil 10 wasit-juri yang 
bertugas pada pertandingan yang sudah memahami betul sistem berbasis komputer pada penilaian pencak silat.

Instrument penelitian yang digunakan adalah untuk mengetahui respon wasit juri pencak silat terhadap penilaian sistem berbasis komputer terhadap penilaian pencak silat. Instrument dibuat dengan menggunakan skala pengukuran rating-scale yang menyediakan jawaban 5 opsi STS, TS, RR, S, dan SS. Setelah itu angket/kuesioner akan diinterprestasikan dengan cara sebagai berikut :

a. Menghitung jumlah skor kriterium

b. Menghitung jumlah skor hasil pengumpulan data

c. Menentukan kategori data sehingga diketahui dari kriteria yang ditetapkan. Secara kontinum dapat dibuat kategori dengan interval,

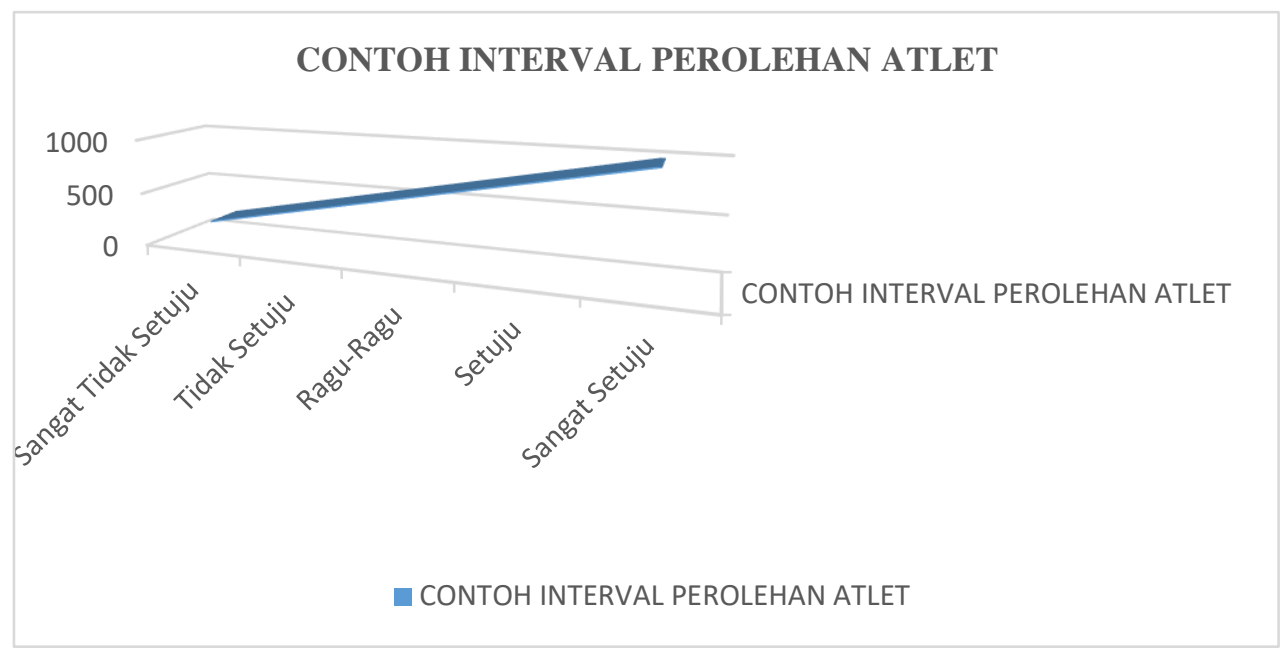

Gambar 1 Contoh Interval Perolehan Atlet

\section{HASIL DAN PEMBAHASAN}

\section{Validitas}

Dari hasil analisis perhitungan validitas dengan menggunakan rumus korelasi product moment pearson, lalu dilakukan pengujian tingkat signifikannya diperoleh 5 soal dengan kriteria validitas yang sangat tinggi dan 3 soal tidak layak atau secara validitas dari 56 soal angket/kuesioner. Sehingga dapat disimpulkan bahwa semua soal yang diujikan yang memiliki interprestasi valid layak untuk digunakan sebagai penelitian dikarenakan nilai korelasinya diatas 0,3 untuk lebih jelasnya dapat dilihat tabel 1 .

Tabel 1 Hasil Uji Validitas

\begin{tabular}{|c|c|c|c|c|}
\hline No Soal & Nilai & Kriteria Validitas & Ketentuan & Keterangan \\
\hline 2 & 0.53 & Sedang & & Valid \\
\hline 3 & 0.44 & Sedang & & Valid \\
\hline 4 & 0.60 & Tinggi & Valid \\
\hline 5 & 0.59 & Sedang & Valid \\
\hline 6 & 0.64 & Tinggi & & Valid \\
\hline 7 & 0.49 & Sedang & & Valid \\
\hline 8 & 0.56 & Sedang & & Valid \\
\hline 11 & 0.49 & Sedang & Valid \\
\hline 12 & 0.71 & Tinggi & Valid \\
\hline 14 & 0.47 & Sedang & Valid \\
\hline 15 & 0.52 & Sedang & Valid \\
\hline 16 & 0.69 & Tinggi & & Valid \\
\hline 17 & 0.49 & Sedang & & Valid \\
\hline
\end{tabular}




\begin{tabular}{|c|c|c|c|c|}
\hline No Soal & Nilai & Kriteria Validitas & Ketentuan & Keterangan \\
\hline 18 & 0.57 & Sedang & & Valid \\
\hline 19 & 0.52 & Sedang & & Valid \\
\hline 20 & 0.51 & Sedang & & Valid \\
\hline 21 & 0.73 & Tinggi & & Valid \\
\hline 22 & 0.62 & Tinggi & & Valid \\
\hline 23 & 0.66 & Tinggi & & Valid \\
\hline 25 & 0.46 & Sedang & & Valid \\
\hline 27 & 0.55 & Sedang & & Valid \\
\hline 28 & 0.63 & Tinggi & & Valid \\
\hline 36 & 0.57 & Sedang & & Valid \\
\hline 38 & 0.45 & Sedang & & Valid \\
\hline 39 & 0.56 & Sedang & & Valid \\
\hline 40 & 0.87 & Sangat Tinggi & & Valid \\
\hline 41 & 0.89 & Sangat Tinggi & & Valid \\
\hline 45 & 0.55 & Sedang & & Valid \\
\hline 47 & 0.67 & Tinggi & & Valid \\
\hline 50 & 0.46 & Sedang & & Valid \\
\hline 52 & 0.51 & Sedang & & Valid \\
\hline 53 & 0.86 & Sangat Tinggi & & Valid \\
\hline 54 & 0.90 & Sangat Tinggi & & Valid \\
\hline 55 & 0.64 & Tinggi & & Valid \\
\hline 56 & 0.86 & Sangat Tinggi & & Valid \\
\hline
\end{tabular}

\section{Realiblitas}

Hasil perhitungan realibilitas dengan menggunakan rumus product moment dari Karl pearson, diperoleh $r_{11}=0,70$ untuk realibilitas soal sistem digital. Sehingga kriteria realibilitas untuk soal sistem termasuk kategori tinggi. Untuk lebih jelasnya dapat dilihat pada tabel berikut :

Tabel 2 Hasil Uji Reliabilitas

\begin{tabular}{lll}
\hline Realibilitas $\left(\mathbf{r}_{\mathbf{1 1}}\right)$ & Koefesien Reliabilitas & Kategori \\
\hline Sistem Komputer & 0,70 & Tinggi \\
Sistem Manual & 0,75 & Tinggi \\
\hline
\end{tabular}

\section{Hasil Penelitian}

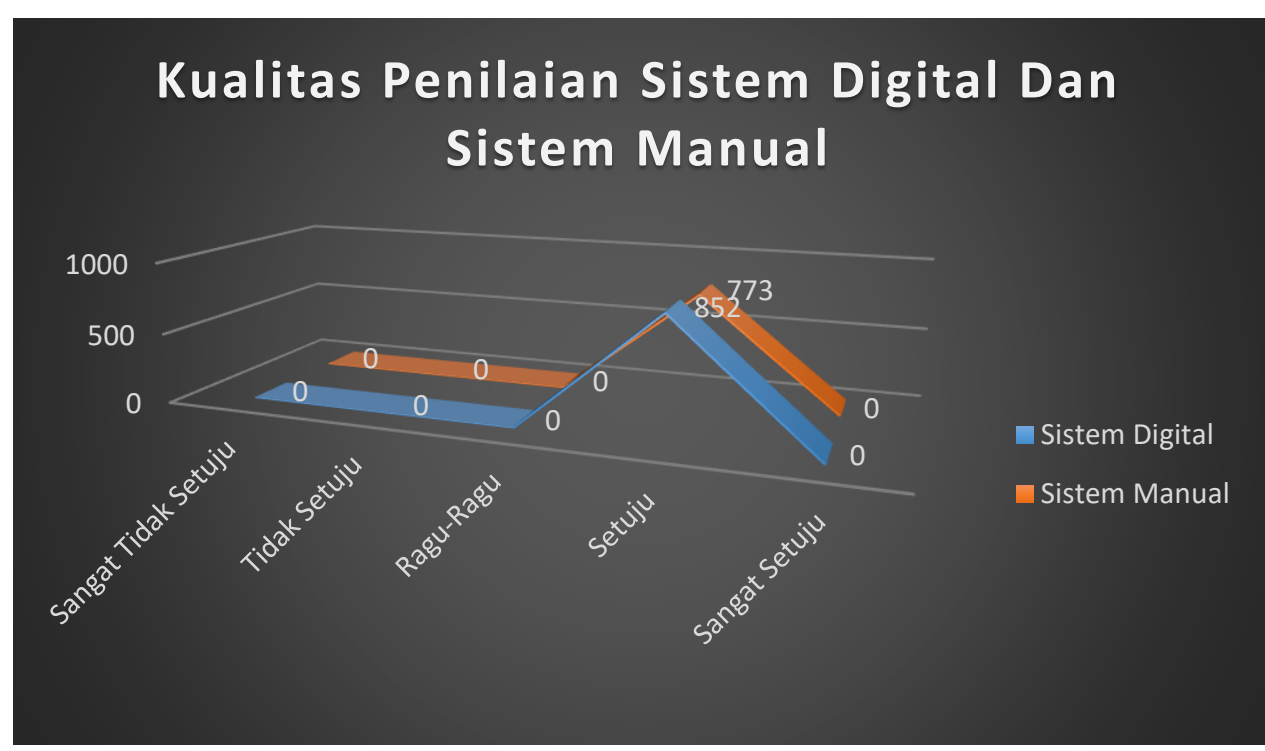

Gambar 2 Kualitas Penilaian Sistem Digital dan Sistem Manual 
Grafik diatas memperlihatkan hasil angket/kuesioner dengan sistem digital hasilnya 852 sedangkan sistem manual 773 dari analisis diatas skor yang paling baik adalah sistem digital yang lebih baik dibandingkan dengan sistem manual. Ternyata responden wasit-juri sangat tertarik untuk menggunakan sistem penilaian pencak silat berbasis komputer dibandingkan dengan sistem manual dikarenakan lebih mudah digunakan dan penilaian.

Dari hasil peneliti yang sedang peneliti dilakukan ternyata sistem digital berbasis komputer dengan sistem manual dalam penilaian pencak silat ternyata yang paling mudah digunakan adalah penggunaan sistem digital berbasis komputer karena lebih cepat dan efektivitas dalam waktu pertandingan pula.

\section{KESIMPULAN}

Berdasarkan penelitian yang telah dilakukan maka peneliti dapat menyimpulkan bahwa sebagai penilaian pertandingan pencak silat sistem berbasis komputer lebih efektif dari pada penilaian sistem manual. Pertandingan pencak silat menggunakan sistem berbasis komputer lebih efesien dalam menggunakannya dan mempermudah wasit juri untuk menilai atlet yang sedang bertanding. Melalui sistem berbasis komputer penilaian lebih transparansi dalam menilai dan meminimalisir kesalahan-kesalahan human error oleh wasit juri itu sendiri. Selain dari pada itu adminitrasi berkas pertandingan lebih dibuat sederhana tanpa menumpuk berkas penilaian.

Berdasarkan data yang telah di olah melalui angket, maka pada sistem berbasis komputer mendapatkan skor sebesar 852 sedangkan sistem manual mendapatkan skor 773, maka dapat disimpulkan penilaian sistem berbasis komputer lebih tinggi dibandingkan sistem manual.

\section{REKOMENDASI}

Setelah melaksanakan penelitian dan membahas hasil penelitian pengaru effektivitas dalam berbasis komputer dengan sistem manual. Penulis menyarankan beberapa masukan yang kirannya dapat menjadi pertimbangan untuk kemajuan dalam pertandingan pencak silat di masa yanag akan datang. Disarankan untuk lebih menggunakan sistem berbasis komputer dalam penilaian pencak sialt, karena lebih terbukti dan efektif dalam pertandingan pencak silat.

\section{UCAPAN TERIMA KASIH}

Penulis mengucapkan terima kasih atas kerjasamanya kepada panitia kejuaraan Pencak Silat PPLM di UNPAD Bandung Se-Nasional pada Tahun 2010 yang sudah memberikan izin untuk melakukan penelitian ini.

\section{DAFTAR PUSTAKA}

Alisyahbana, Iskandar. 2000. Teknologi dan Perkembangan. Jakarta : Yayasan Idayu

Anglin, Gary J. 1991. Instructional Technology: Past, Present and Future.

Englewood : Libraries Unlimited

Anonim. (2000) . Gema Pencak Silat. Jakarta: Pondok Pustaka.

Atok Iskandar dkk. (1992). Pencak Silat. Jakarta: Proyek Pembinaan Tenaga Kependidikan Dirjen Dikti Dep. Pdan K.

Departemen P dan K. (1989). Tuntutan Pelajaran Olahraga Pencak Silat untuk Sekolah Dasar. Jakarta: Humas Depdikbud. 
Notosoejitno. (1989). Sejarah Perkembangan Pencak silat di Indonesia. Jakarta: Humas PB IPSI

Nursid Sumaatmadja, Manusia Dalam Konteks Lingkungan Sosial Budaya dan Teknologi, Bandung, Alphabeta, 2004.

Ikatan Pencak Silat Indonesia (2007) Hasil Munas XII Perarturan Pertandingan pencak Silat

--------. (2000). Pencak Silat World Championship 2000. Jakarta: Humas PB IPSI.

Persilat. (1985). Keputusan Sidang Umum Pertama; Persekutuan Pencak Silat antara Bangsa. Kuala Lumpur : PESAKA.

O’ong Maryono. (1998). Pencak Silat; Waktu Merentang. Yogyakarta.: Pustaka Pelajar. 